\title{
Comunidad y Movimientos Sociales
}

\section{Carlos Rojas Reyes}

Parto de una definición generalísima de comunidad para pasar a su comprensión como don. Ciertamente, un don muy especial, en cuanto es un horizonte de sentido indispensable para la formación de los ideales de la humanidad -y para el surgimiento de otro mundo posible-, y al mismo tiempo, como colocado por fuera de la realidad, existiendo en un espacio exterior de imposibilidad.

La globalización actualiza el debate sobre el comunitarismo y lo coloca bajo una nueva luz, especialmente para dejar de verlo como aquello que se ha perdido en un pasado ideal; y tomarlo ante todo como una construcción que el presente nos exige. Dudas y ambigüedades resultan de este enfoque comunitario, porque contiene esperanzas y peligros que no se ve cómo puedan resolverse. Para concluir, me pregunto: hasta qué punto los movimientos sociales antiglobalización son una forma de comunidad, una promesa de comunitarismo; e igualmente, en qué medida escapan a este paradigma.

¿Es posible pensar los movimientos sociales antiglobalización como prefiguraciones de la comunidad que viene? ¿Puede el comunitarismo servir de horizonte de sentido para la comprensión de los movimientos sociales y para orientar sus formas de acción y de organización? Y, sobre todo, ¿cuáles son los debates actuales sobre el tema que se vinculan con estos movimientos y cómo posicionarse en torno a ellos? Para aproximarnos a la noción de comunidad, tomamos cuatro aspectos complementarios para establecer un significado provisional de comunidad:

El primer elemento se refiere al aspecto sociológico de la comunidad, en donde la existencia y la reproducción ampliada de sus miembros dependen directamente e indispensablemente de los otros miembros:

...exposición común de los unos a los otros, donde la existencia es, por definición compartida, es decir, constitutivamente abierta a la copresencia del otro (Fistetti, 2003: 10).

Filósofo. Profesor y director de investigaciones de la Facultad de Ciencias Económicas de Cuenca. E-mail: crojas@ucuenca.edu.ec 
El segundo elemento retoma los aspectos simbólicos e imaginarios de la comunidad, en tanto ésta es un modo de representación del mundo que se comparte con los demás miembros del grupo y que sirve como guía para organizar el conjunto de la vida social, en cualquiera de sus aspectos: “...aquellos que han consentido en ir juntos en cuanto al símbolo" (ibíd.: 11).

Para esta reflexión recojo una noción construida en otro trabajo sobre mundos simbólicos:

El mundo simbólico es ante todo un horizonte que posibilita y delimita el campo de las experiencias. Nos dice qué puede constituir una experiencia y qué no puede serlo. Parte de una pluralidad de dimensiones del mundo, en donde se abren un conjunto de posibilidades ubicadas en la historia y que son ellas mismas historia. La experiencia que se corresponde con los mundos simbólicos pertenece al orden cultural, con un conjunto de representaciones sobre lo existente, pero también como una apertura a experiencias que se ubican en un plano especial, que generalmente se identifica con el mundo de los espíritus (Rojas, 1994: 93 y ss.).

En tercer lugar está la comunidad como don, como intercambios que se dan entre la comunidad y sus miembros, o entre ellos que escapan a la lógica del valor y a las reglas del mercado capitalista. El don presupone la inexistencia de cualquier tipo de calculabilidad. Si el otro hace un cálculo respecto de algún tipo de equivalente para devolverme, de alguna manera, lo que le ha sido donado, se quiebra la lógica del don; desaparece el don y aparece el intercambio mercantil, aunque sea de manera larvada.

El don como elemento de la dinámica de las relaciones sociales de la comunidad se convierte en el elemento discriminador respecto de las formas de organización guiadas por la ganancia en un determinado mercado. Desde luego aquello que se da en el don puede ser de lo más variado, va desde objetos hasta elementos simbólicos, así podemos dar fe o dar nuestro tiempo. Sintetizando estos elementos, tendríamos que la comunidad es un grupo humano en el cual la existencia de sus miembros depende directamente de los otros, en donde estos comparten un orden simbólico, y cuya forma de vida se basa en el don (Fistetti, 2004).

En cuarto lugar, está la reciprocidad: retomo la aproximación que realiza Esterman al concepto de reciprocidad como el elemento en el cual se expresa el conjunto de la cosmovisión andina: 
A cada acto corresponde como contribución complementaria un acto recíproco. Este principio no solo compete a las interrelaciones humanas (entre personas o grupos), sino a cada tipo de interacción, sea esta intra-humana, entre hombre y naturaleza, o sea entre el hombre y lo divino (Estermann, 1998: 132).

Esto permite abrir un campo muy amplio para entender las relaciones no solo al interior de la sociedad, sino de la naturaleza con la sociedad, en el marco de una cosmovisión integral. A partir de este acercamiento básico, entremos en algunos de los debates en torno a la comunidad para dilucidar si los movimientos sociales antiglobalización pueden ser comprendidos desde esta perspectiva.

\section{La comunidad como don}

En este apartado realizo una lectura a Derrida en sus textos como el don, especialmente en la reinterpretación de Marcel Mauss e introduzco en sus consideraciones la noción de comunidad. Trato de responder a una pregunta básica: ¿ese don, que Derrida expresa de diversas maneras, no sería sino la comunidad que viene aunque considerada como imposible de alcanzar? Y más adelante, ¿no sería la comunidad mundial un don en este preciso sentido que los movimientos sociales antiglobalización tratan de alcanzar?

'Don es dar algo a alguien', pero de tal manera que este acto escapa a la lógica de la demanda que obliga a ser recíproco, a exigir un bien similar en cambio de lo dado. Sin embargo, esta formulación del don conlleva una serie de paradojas en su interior; imposibles de resolver. Hay un primer plano en donde se produce la incompatibilidad absoluta entre el don y la lógica capitalista, en la medida en que el don excluye de manera completa el cálculo sometido a un equivalente general para producir una ganancia que, a su vez, es objeto de apropiación privada.

El capital destruye el don, aun el don como reciprocidad, como deuda, como forma de intercambio no basado en el cálculo económico del dinero y la mercancía. Pero, dentro del don y fuera de la esfera del capital, persiste una paradoja que se extiende a todos los fenómenos que tengan esta estructura, tales como la justicia o la amistad, en la que se incluye la comunidad. 
Siguiendo a Marcel Mauss, Derrida sostiene la interpretación del don como absoluto opuesto al don como reciprocidad, por ejemplo, en la forma como lo ve Maurice Godelier, que justamente pertenece a otra tradición interpretativa (Derrida, 1995). El don es aquello que se da sin que se exija nada a cambio, es una donación completa, absoluta, sin más; porque cualquier elemento de retorno, de reconocimiento, iría en contra de lo que es y de este modo el don se pervertiría. Si al recibir el don hacemos algún cálculo de equivalencia estaríamos dejando la esfera del don; si devolvemos algo aun por fuera de este cálculo, esta reciprocidad también mataría al don, porque de este modo el don estaría creando una deuda.

Si hay deuda, el don deja de ser absoluto, se convierte en don recíproco. Desde luego, esta deuda puede ser de lo más diversa, que le permite englobar desde la deuda puramente simbólica, hasta imaginaria, hasta una deuda concreta que se expresa en la entrega de determinados bienes concretos, que se dan como forma de intercambio. Llegamos a la paradoja de que el don para ser tal -don puro- debe ser ignorado por el que da y por el que recibe, tiene que excluir cualquier forma de intercambio, debe permanecer totalmente oculto a la mirada de todos para que no se convierte en deuda social, familiar o personal.

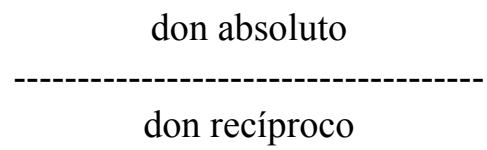

Don absoluto y don recíproco ocupan planos que están separados, en donde el acceso al don absoluto se ha vuelto imposible. El don es así, lo que no puede nombrar, lo que no se puede decir. El don es dación pura sin reciprocidad, porque esta última implica algún tipo de devolución. El don puro se torna indecible e intemporal, mientras el capitalismo penetra en el don recíproco para irlo convirtiéndolo, poco a poco, en calculabilidad a través del equivalente general, sometido a la valorización del valor de cambio.

El don escapa al tiempo porque lo que se dona es precisamente el tiempo; el don da el tiempo aunque se coloca en su exterioridad, ciertamente una exterioridad imposible, porque cuando el don se da, se pierde, se vuelve reciprocidad, se pasa del primer plano al segundo plano. 
Este es el proceso por el cual todo es histórico-concreto, todo se temporaliza, se ubica en el plano de las temporalidades por un proceso de diferimiento. Diferir es dejar para mañana lo que se puede hacer hoy. De hecho, solo existimos porque podemos diferir, porque el tiempo es del orden del postergar, porque abre una brecha en la inmediatez del instante permitiendo la teleología de la existencia humana. Vivimos en el diferir, porque de lo contrario la serie de eventos se darían en el presente, que se vería saturado. Este es precisamente el origen del lapso entre el don absoluto y el don recíproco, que crea la diferencia entre los dos y también su oposición; esto es, la imposibilidad de que el don absoluto se mantenga como tal en el momento en que entra los procesos históricos. El tiempo transforma el don absoluto en don recíproco:

$$
\text { Don puro -------- temporalización ---------- don recíproco }
$$

La dinámica que va de un punto a otro tiene profundas implicaciones en el orden de lo social y de lo político: el poder constituyente se convierte en poder constituido, ${ }^{2}$ la justicia se vuelve derecho, la amistad se torna interés, las comunidades ideales se convierten en reales con todos sus alcances, limitaciones y perversiones con las que las conocemos.

don absoluto: justicia

don recíproco: derecho

don absoluto: comunidad

don recíproco: comunidades efectivamente existentes

El texto de Derrida, Dar (el) tiempo, expresa con claridad esa tendencia de concebir a la comunidad como aquello cuya experiencia no puede darse y no puede pensarse sino de manera negativa. En El tiempo del rey, se coloca en toda

2 Analizo en otra parte de este trabajo el paso del poder constituyente al poder constituido y su relación con la soberanía. 
su dimensión la cuestión del don, junto con la paradoja que acarrea, que está ligada con la dinámica del tiempo de una manera bastante peculiar. El tiempo es algo que no se puede dar. Cuando decimos que damos nuestro tiempo, en realidad, entregamos algo que está en el tiempo, pero no el tiempo mismo. Este por su propia naturaleza escapa, se torna siempre inaprensible:

El tiempo, en todo caso, no da a ver nada. Es, como poco, el elemento de la invisibilidad misma. Sustrae todo lo que se podría dar a ver. El mismo se sustrae a la visibilidad. No se puede sino ser ciego al tiempo, a la desaparición esencial del tiempo (Derrida, 1995: 16).

Así como el fenómeno del tiempo se nos escapa a pesar de que vivimos inmersos en él -sin poder escapar-, sin que haya exterioridad posible; de la misma manera el don representa una exterioridad que nos constituye. Pero, ¿por qué el don tiene una estructura similar al tiempo? Comencemos señalando que el don es lo imposible:

No ya presentar la cosa, a saber, aquí lo imposible, sino tratar de dar a entender o a pensar bajo su nombre, o bajo algún otro nombre, esa cosa imposible, ese imposible mismo (ibíd.).

Una imposibilidad tan radical que incluso el lenguaje no alcance a decirlo plenamente, que el pensamiento no puede pensarlo, que el inconsciente no puede retenerlo, no bajo la forma de un olvido reprimido. Y, nuevamente surge la pregunta ¿qué tiene el don que se escapa a cualquier modo de representación ya que es lo imposible en cuanto imposible? Cuando damos algo bajo la forma de don, como individuos, colectividades o comunidades, entendemos que tiene la forma de:

Alguna persona (A) tiene la intención-de-dar B a C. alguna persona tiene la intención-de-dar o da alguna cosa a otro alguien (ibíd.: 20).

En el acto de donar damos algo a alguien, aunque lo que demos sea un presente, o demos fe o demos crédito. Es indispensable que algo de alguien se traslade al otro, de lo contrario no hay don y esto lo entendemos todos de manera directa y primaria. Mas, justamente en este movimiento de donación, por sus propias características, el don queda anulado: 
Y esto es así porque lo imposible, que aquí parece que se da a pensar es que las condiciones de posibilidad del don (alguna persona da alguna cosa a otro alguien) designan simultáneamente las condiciones de imposibilidad del don. Y de antemano podríamos traducir de otro modo: esas condiciones de posibilidad definen o producen la anulación, el aniquilamiento, la destrucción del don (ibíd.: 21).

El don presupone la inexistencia de cualquier tipo de reciprocidad. Si el otro hace un cálculo respecto de algún tipo de equivalente para devolverme, de alguna manera, lo que le ha sido donado, se quiebra la lógica del don, desaparece el don y aparece la reciprocidad o el intercambio, aunque sea de manera larvada. A tal extremo que el don exige que nada sea devuelto, ni siquiera un gesto de gratitud, ningún tipo de deuda simbólica, hasta el recuerdo de que ha habido donación tiene que desaparecer.

Derrida choca frontalmente con la tradición antropológica y con toda razón:

Aunque todas las antropologías, e incluso las metafísicas del don, con toda razón hayan tratado conjuntamente como un sistema, el don y la deuda, el don y el ciclo de restitución, el don y el préstamo, el don y el crédito, el don y el contradon, nosotros desistimos aquí, de forma enérgica y tajante, de esta tradición. Es decir, de la tradición misma.

El don para ser tal tiene que desaparecer hasta del rastro del inconsciente, de la memoria colectiva, de cualquier proceso de olvido que luego pueda retornar a la conciencia. Finalmente llegaríamos al don en el momento en que este desaparece como tal de nuestra presencia. Indudablemente este camino sin salida al que es conducido el don exige una respuesta; Derrida ya no la encuentra en la metafísica de la presencia de Heidegger, sino en su propia formulación de una huella que es huella de sí misma y no remite a ningún ser oculto. Por esto, es indudable que Derrida se orienta a resaltar aquellos aspectos del don que muestran empíricamente, esta imposibilidad de tener una experiencia de ellos y de pensarlos. De allí que la reflexión sobre el don se orienta a la desmesura, al exceso, a aquello que rebasa el campo de la experiencia cotidiana y se torna acontecimiento extraordinario.

Retomando a Mauss, señala los objetivos de su trabajo: 
1. Lograr (res)guardar una especificidad originaria del proceso del don con respecto a la fría racionalidad económica, al capitalismo y al mercantilismo -y así, reconocer que el don es aquello que pone en marcha el círculo del intercambio económico; 2. Lograr describir la simbolicidad que atraviesa la fría razón económica, rendir cuenta de los fenómenos religiosos, culturales, ideológicos, discursivos, estéticos, literarios, poéticos, que son inseparables del proceso don, y lo organizan en el interior del hecho social total (ibíd.: 48).

Del hecho social como comunidad:

El don sería originario; sería el verdadero productor del valor puesto que es el valor de los valores en sí mismo. Tal como dice Valéry del espíritu, el don sería a la vez un valor y el origen, que no tiene precio, de todo valor (ibíd.: 50).

El significado del potlach:

$\mathrm{Su}$ lenguaje se vuelve loco en el momento en que, en el potlach, el proceso del don se arrebata, que dice Mauss al respecto: "no se trata siquiera de dar ni de devolver, sino de destruir a fin de no querer siquiera que parezca que desean que se les devuelva nada"...La paradoja misma de "dar lo que no se tiene..." (ibíd.: $52)$.

Locura que se convierte en coextensiva con toda la sociedad:

Todas estas cuestiones conciernen a una determinada locura del don que es, ante todo, locura de la diseminación del sentido don (ibíd.: 60).

Podemos detenernos un momento aquí y señalar que el don es probablemente el aspecto fundamental de las comunidades sin el cual éstas no existirían. ¿Significa entonces que junto con la imposibilidad del don, tenemos la imposibilidad de la comunidad? ¿Es esta la experiencia y la representación que Occidente no puede tener, que se le escapa como una exterioridad que permite que exista todo lo demás, como unos límites externo constitutivo, como una exclusión inclusiva?

El lenguaje de Derrida se estrella contra esta imposibilidad nuclear de Occidente, de su pensamiento que está atrapado en la lógica del intercambio, aunque ésta tenga la forma de la reciprocidad; aunque en la mayoría de casos se trate 
simple y directamente del intercambio de mercancía por dinero y de dinero por mercancía. Es el ciclo feroz M-D-M' el que habría atrapado al mundo entero, en la globalización neoliberal, en esta dinámica del intercambio, de la ganancia, de la cual nada podría escapar. Todo lo demás como el tiempo, el don y la comunidad quedan completamente excluidos, imposibilitados de ser un acontecimiento y de ser guardados ni siquiera en el inconsciente.

Rastreemos las connotaciones que las afirmaciones precedentes tienen para la cuestión de la justicia, que es crucial para el tema del otro mundo posible colocado como el lema crucial de los movimientos sociales antiglobalización. Si relacionamos a la justicia con la comunidad como don, entonces la justicia es imposible, sobre ella no podemos tomar decisiones -indecidible-, sin embargo tiene una relación inmanente e intrínseca al derecho. El derecho, que es finalmente lo único efectivamente existente, solo puede existir si se fundamenta en la justicia. Esta es el fundamento del derecho, que es el actúa en el tiempo, en la realidad histórico-concreta.

Respecto del tiempo, la justicia es anacrónica, no pertenece a ninguna época; es profundamente inactual. Esta anacronía se convierte en ucrónica en el momento en que penetra en la realidad para criticarla, como un espectro que recorre todo el derecho, para mostrarla como una serie de estructuras y sucesos que carecen por sí mismos de basamento sólido, que su verdad está en otra parte, precisamente en la justicia. Esta u-cronía viene de la misma raíz que u-topía: lo que está fuera de lugar, más allá de cualquier lugar, quizás lo que simplemente carece de lugar y por lo tanto es imposible. Pero, la justicia no tiene el sentido de una utopía, como una especie de construcción más allá de cualquier alcance, como una construcción meramente ideal pero básicamente ineficaz.

Lo que le diferencia de la utopía es que el derecho, como realmente existente, tiene allí su origen y su fundamento, sin poder prescindir de ella; la justicia no puede desaparecer sin más como horizonte de sentido, no es una elaboración cultural más o menos fantasiosa, sino un principio organizador de toda experiencia del derecho, como el ámbito que intenta contener en todo momento actos que sean justos, o dotarnos de la capacidad de distinguir el bien del mal. Sin embargo, el don puro está lejos de ser aquello que no se puede decir, pensar, ubicar en el tiempo; por el contrario, está allí como la condición de posibilidad 
del derecho, interés, comunidad, que sin su referente no podrían ni siquiera existir.

Esta es otra paradoja, tal vez de una complejidad con consecuencias tan vastas como la primera: no se trata solamente de que el don absoluto al atravesar la barrera de la temporalidad deviene algo opuesto, que lo niega, que cambia de absoluto a contingente, de puro a empírico, sino que el don puro es simplemente imposible. Ahora bien, es un tipo muy especial de imposibilidad ${ }^{3}$ porque -como he dicho-, es fundamento, origen, de todo lo que efectivamente existe.

No existe la comunidad tal como la conocemos -o ninguna otra- sino en la medida en que tiene como horizonte de sentido a la comunidad absoluta, no hay reciprocidad sino en cuanto hay don puro, no hay poder constituido sino en la medida en que un poder constituyente se ha convertido en tal; es una natura naturans que no tiene otra alternativa que volcarse de manera completa -expresarse- en la natura naturata. Solo existe lo inmanente; nada hay por fuera, en el exterior de las comunidades efectivamente o virtualmente existentes $y$, sin embargo, su fundamento imposible, indecible, inaprensible está fuera. El sentido del mundo está fuera del mundo. ${ }^{4} \mathrm{Y}$ esto es causa de una gran desazón: "...el miedo de la indecidibilidad del sujeto del humanismo" (Spivak Gayatri, 2003: 25).

El don puro, que es la comunidad como tal, es entonces horizonte de sentido e historia de sucesos. Solo podemos pensar, inventar, crear efectivamente en la realidad social y política, comunidades contrastadas contra este fondo que es el don comunitario; y esto define qué se puede dar y qué no se puede dar en el plano histórico-concreto, porque delimita los sucesos que son posibles, la gran variabilidad de tipos de comunidades que se han dado en la historia de la humanidad y las condiciones de posibilidad para nuevas comunidades e incluso para una comunidad mundial.

3 Quizás se podría discutir si esta imposibilidad es de principio o de hecho, pero es una cuestión que no parece importante, porque queda clara que en las actuales condiciones de la humanidad no podemos alcanzar esa comunidad ideal como don puro; tendemos hacia ella, otras generaciones se plantearan si estas paradojas son resolubles o no.

Sería interesante una lectura del Tractatus de Wittgenstein en esta dirección no mística. 


\section{La comunidad en la sociedad globalizada}

De una manera aún más concreta cabe preguntarse por la necesidad de un planteamiento comunitario en una sociedad liderada por la globalización neoliberal, como una alternativa a ésta, que permita construir ese otro mundo posible. Posiciones antagónicas y confrontadas se dan en los debates actuales sobre la comunidad, en el contexto de las cuales intentaré delinear una posición que, sobre todo, abra un campo para la reflexión y para la acción al interior de dichos movimientos; no solo con un finalidad teórica, de comprensión, sino práctica, de acción efectiva contra el avance de la mundialización capitalista.

El texto sugerente de Agamben, La comunidad que viene, sirve de pórtico a la temática:

...pero el tener lugar de cada ser singular es siempre ya común -un espacio vacío, ofrecido a cada uno, una hospitalidad irrevocable (Agamben, 2003: 24.4).

Precisamente el título de este libro evoca la pregunta clave: ¿podemos considerar que los movimientos sociales antiglobalización son la prefiguración de la comunidad que viene? Y que llegará como promesa de esa irrevocable hospitalidad que parece estar contenida en la noción y las expectativas que ponemos sobre la o las comunidades, sobre aquello que siempre ya es común. Aunque se abre simultáneamente la problemática de "an absolutely unrepresentable community" (ibíd.: 24.5); aludiendo a las dificultades que se encuentra en su concreción y por ende, en su comprensión. Jean-Luc Nancy (1991) coloca a la comunidad en la brutalidad de la historia contemporánea: ¿cómo plantearse un comunitarismo cuando estamos ante el fracaso del comunismo, ante la caída de los socialismos realmente existentes que se levantaron en nombre de la comunidad como superación de la sociedad capitalista? Desde el nombre mismo del libro se percibe la dirección que su reflexión tomará: inoperative-desoeuvrée-: que no funciona, que es inefectivo y que marca el decurso de las sociedades modernas:

El testimonio más grave y más doloroso del mundo moderno, el que implica posiblemente al resto de los testimonios a los cuales esta época deba responder (en virtud a cierto decreto o necesidad desconocida, porque de nosotros testimonian 
también el agotamiento de pensar a través de la historia), es el testimonio de la disolución, de la dislocación, o de la conflagración de la comunidad (ibíd.: 1).

Y que fue vinculado al término comunismo como la más alta expresión de la comunidad, como la realización del reino de la libertad por encima del reino de la necesidad, como la promesa suprema de la felicidad. Vivimos entonces, en una época en donde esta promesa se ha roto y por esto ha dejado de estar frente a nosotros como una perspectiva efectivamente actuante, ha dejado de ser una guía para la acción, se ha vuelto inoperante.

No hubo realmente comunismo sino de manera muy embrionaria; fue pronto reemplazado por sociedades burocráticas que inventaron nuevas formas de autoritarismo y represión y que traicionaron los ideales contenidos en las revoluciones. De hecho, la oposición política al estalinismo adoptó la comunidad como un lema que había que rescatar y realizar; por ejemplo, en los consejos obreros o en otros modos de autogestión. Sin embargo, estas experiencias embrionarias jamás lograron desarrollarse completamente y tarde o temprano fueron derrotadas.

Entonces Jean-Luc Nancy da un salto crucial en su razonamiento: hay que cuestionar a fondo la idea de que hubo una comunidad y la perdimos; hay que clausurar la sensación de nostalgia que viene ligada a la noción de comunidad y que provoca secuencialmente retrocesos románticos:

Pero es aquí que debemos sospechar de la conciencia retrospectiva de la comunidad perdida y de su identidad... en primer lugar porque parece haber acompañado al mundo occidental desde sus inicios: en cada momento en su historia, Occidente se ha echado encima a la nostalgia de una comunidad arcaica que ha desaparecido, y ha deplorado la pérdida de la familiaridad, de la fraternidad y de la convivialidad (ídem: 10).

Nada hemos perdido, de nada tenemos que sentirnos nostálgicos; incluso en el caso de la comunidad andina, hay que mostrar las limitaciones de las formas de vida incásicas y la imposibilidad de convertirlas en modelos de vida contemporáneos sin más, como si fuera posible retroceder a una especie de sociedad ideal que ya no está más entre nosotros. Es posible cuestionar, desde esta perspectiva, nociones como las de Weber (cfr. Weber, 1977), para estable- 
cer otra relación entre sociedad y comunidad, que nos proveen de una visión muy diferente a la que de manera casi estándar se maneja en nuestros entornos académicos:

La sociedad no fue construida sobre las ruinas de una comunidad. Emergió de la desaparición o conservación de algo -tribus o imperios- quizás no relacionado con lo que nosotros llamamos comunidad o sociedad (ídem: 11).

¿Dónde está la comunidad respecto de la sociedad si no se ubica detrás de ella como un pasado ideal perdido? Está delante, frente a ella, aunque de una manera paradójica:

De modo que la comunidad, lejos de ser lo que la sociedad que se ha perdido, es lo que nos ha sucedido - pregunta, espera, evento, imperativo- en el despertar de la sociedad (ídem: 11).

Ahora bien, el problema radical es que aun planteada la situación de esta manera, la sensación de pérdida no desaparece y se ha convertido en constitutiva de la comunidad; la pérdida es la forma de ser de la comunidad, le es inherente. Y lo es en cuanto la comunidad no puede ser alcanzada, no se puede llegar a ella. Cualquier experimento local o estatal de plantear la comunidad no se dará como tal. La comunidad es imposible y por eso inoperante, aunque sin ella la sociedad no puede efectivamente despertar. Junto a la conciencia de la necesidad y la nostalgia de la comunidad, aparece irremediablemente la percepción de su fracaso histórico:

El reverse de la nostalgia de una comunidad perdida en la conciencia del inmenso fracaso de la historia de las comunidades (ídem: 18).

La conclusión de Nancy no puede ser sino pesimista: ¿No sería mejor como una conclusión mucho más racional y apegada a la historia dejar de considerar a la comunidad como un proyecto posible y verlo únicamente como ese horizonte real y de sentido inalcanzable? Dos décadas después de la caída del muro de Berlín, nos encontramos que el tema de comunidad se coloca otra vez en nuestra perspectiva y que la necesidad de replantearse las colectividades pro- 
viene de los propios colectivos antiglobalización, que exigen cada vez más una teorización acorde con sus discursos y prácticas.

En términos de Spivak, todavía ponemos detrás de la cultura a unos colectivos, aunque la mayoría de veces no seamos conscientes de las implicaciones de este gesto:

Para asumir la cultura debemos asumir a su colectividad. Con todo asumimos generalmente la colectividad en base de su cultura (Spivak Gayatri, 2003: 27).

Retomando a Derrida, Spivak muestra que la comunidad va de la mano de la fraternidad, que se vincula directamente con las políticas de la amistad, que "no hay política sin colectividad" y que no hay colectividad sino de amigos (ibíd.: 28 y ss.). Esto es, la inmanencia del otro. En una aproximación más sociológica, Zigmunt Bauman (2003) reflexiona sobre los orígenes y el destino de las comunidades en las actuales sociedades, además de las paradojas a las que lleva.

En un mundo en donde todos los riesgos son posibles y están frente a nosotros a diario, por más que no queremos verlos, la comunidad se presenta como la única posibilidad de organización social que nos proteja:

La comunidad es un lugar cálido, un lugar acogedor y confortable. Es como un tejado bajo el que cobijarse cuando llueve mucho, como una fogata ante la calentar nuestras manos en día helado (ibíd.: 7).

Aunque inmediatamente el dilema se hace presente; entre la comunidad ideal y la comunidad real siempre habrá una distancia insalvable, porque tiene la estructura del don y la reciprocidad. La comunidad como don puro está más allá de lo que es ahora alcanzable. Además la comunidad parecería exigir renuncias que terminan por abolir aquello que buscamos, que incluso pueden ser peores que el mundo que vivimos:

Pero lo que pone en cuestión esta imagen sin mácula es otra diferencia: la que hay entre la comunidad de nuestros sueños y la comunidad realmente existente: una colectividad que pretende ser la comunidad encarnada, el sueño cumplido y que... exige lealtad incondicional y trata todo que no esté a la altura de tal lealtad como un acto de traición imperdonable (ídem: 10). 
El mundo contemporáneo nos arroja a esa contraposición entre dos bienes a los que consideramos irrenunciables; la necesidad de una sociedad organizada de forma comunitaria y la libertad, de hecho la libertad individual y no solo colectiva a la que no queremos ni debemos renunciar. Atrapados entre los cuernos del dilema terminamos despedazados: o bien sostenemos que la comunidad es imposible y nos entregamos al individualismo burgués con furia, porque en último término todo colectivo termina por ser opresiva; o bien, percibimos que hasta para el individuo burgués - por ejemplo, para el inversionista- es indispensable la colectividad y empieza la nostalgia de la comunidad:

Elija uno lo que elija, algo se gana y algo se pierde. Perder la comunidad significa perder la seguridad; ganar la comunidad, si es que se gana, pronto significará perder la libertad. La seguridad y la libertad son dos valores igualmente preciosos y codiciados que podrían estar mejor o peor equilibrados, pero que difícilmente se reconciliarán de forma plena y sin fricción (ídem: 11).

Bauman no puede sino construir una frase brutal que no deja de perseguirnos: "Siendo humanos, no podemos ni cumplir la esperanza ni dejar de esperar" (ídem: 11).

Parecería como si el ángel de la historia de Benjamín se hubiera convertido en el ángel exterminador de Buñuel:

El Ángel de la Historia alcanza dando la espalda al futuro, por lo que sus ojos están fijos en el pasado... Walter Benjamin da a entender que el progreso no es una persecución de los pájaros del cielo, sino una necesidad frenética de huir de los cadáveres esparcidos por los campos de batalla del pasado (ídem: 25).

Para Bauman hay dos fuentes del comunitarismo al interior de una sociedad de riesgo, en donde las seguridades se pierden a cada rato, aunque los anclajes ontológicos se reconstituyan, ciertamente solo para volverse a perder. Es la dinámica interna de las sociedades contemporáneas las que nos conducen a esa esperanza imposible de la comunidad o a esa esperanza de la comunidad imposible. Un primer origen en encuentra en:

Por mucho que estimen su autonomía individual y por mucho que confien en su capacidad personal y privada para defenderla eficazmente y para hacer buen 
uso de ella, los miembros de la elite global sienten en ocasiones la necesidad de pertenencia. Saber que uno no está solo y que los propios anhelos personales son compartidos por otros tienen un efecto reconfortante (ídem: 77).

El segundo origen está en la repetición de las conductas vinculadas a las formas de vida capitalistas, sobre todo en el consumo y en los medios de comunicación de masas: la comunidad de los que compramos y usamos lo mismo:

Debe ser fácil de desmontar como fácil ha sido de componer. Debe ser y permanecer flexible, sin ser nunca más que hasta nuevo aviso y mientras dure la satisfacción. Su creación y desmantelamiento deben ser determinados por las elecciones que toman quienes la componen: por sus decisiones de prestarle o retirarle fidelidad... (ídem: 79).

En este segundo origen las comunidades se convierten en meros simulacros; nos sentimos identificados porque compramos y consumimos lo mismo, desde un electrodoméstico hasta un cantante, pasando por un candidato a cualquier elección política; pero este tipo de comunidad apenas sí es un pálido reflejo de una verdadera comunidad, porque resuelve nuestras necesidades de seguridad, protección, afecto, pero lo hace exclusivamente en el plano imaginario:

Los ídolos obran un pequeño milagro: hacen que suceda lo inconcebible; conjuran la experiencia de la comunidad sin una comunidad real, la alegría de la pertenencia sin la incomodidad de estar atado. La convivencia se siente como real, se vive como real, pero sin embargo no está envenenada por la tenacidad, resistencia e inmunidad de los deseos individuales... (ídem: 84).

Hemos alcanzado a la comunidad y nos encontramos que no escapan a la lógica del capital y de la moda:

Las comunidades que se forman en torno a ellos son comunidades listas para el consumo, comunidades instantáneas para el consumo instantáneo; son totalmente desechables después de su uso (ídem).

Lastimosamente los dos tipos de comunidades: la de la seguridad y la del consumo, tienden a solaparse y a confundirse en una sola. ¿Cómo escapar, entonces, a la férrea paradoja de la comunidad y del don, sin recaer en formas de 
intercambio o sin proponer una ley anterior a la comunidad que le origine de alguna manera trascendental? ¿Son realmente incompatibles el don como reciprocidad, la comunidad como intercambio no capitalista con el don radical que no debe tener un contra-don? Quizás el otro camino a recorrerse, siguiendo el rastro contemporáneo de los movimientos sociales antiglobalización, especialmente en su expresión en el Foro Social Mundial, como prefiguración de la comunidad y por lo tanto, como posibilidad del don, si mostramos la articulación entre el don antropológico .-por decirlo de alguna manera para distinguirlo del otro- y el don -sin más, sin contra-don-.

Existe don en su versión antropológica, como alguna forma de devolución, aunque fuera puramente simbólica, solamente allí en donde se da el don. El don sin contra-don es el que crea la posibilidad del don como reciprocidad. Solo en donde hay comunidad se da la reciprocidad. Donde hay tiempo, damos algo a alguien, damos un presente, nos hacemos presentes con un presente.

Quiero decir que la comunidad no es solo una forma de organización de los seres humanos, de los colectivos; sino que es una forma en la medida en que primariamente es un contenido.

Retomando el debate con Derrida, se dirá que los modos de donación tienen siempre la forma de dar algo a alguien, del acto de 'A' que da 'B' a 'C'. Pero, esta fórmula ha caído históricamente en el capitalismo en la lógica de la ganancia, en el proceso del intercambio monetario, en la reificación de las relaciones sociales. Por fuera de esta cosificación del intercambio simbólico, la reciprocidad de las comunidades no capitalistas se da, nunca de forma completa ni pura, porque existe otra donación, otro don co-originario que lo sustenta. Este don -que es el don que exige Derrida con razón- es único. Es lo único que no se da bajo la forma de don y contra-don, sino que se da como don sin más. Ese don es la propia comunidad que es tanto la forma del darse del don antropológico como el contenido del don sin más.

El camino que la comunidad transita para devenir como posible es que se vuelva contenido del don: cuando intercambiamos, cuando somos recíprocos, cuando reconocemos una deuda con el otro, cuando le devolvemos el reconocimiento de sus derechos que a su vez me está reconociendo, lo que no es objeto de intercambio es la propia comunidad. La comunidad es el único don que 
escapa a la deuda, a la devolución, aunque haga posible y visible la deuda y la devolución, aunque sea la fuente de la reciprocidad.

\section{Los movimientos sociales antiglobalización como prefiguración de la comunidad que viene}

El conjunto de debates de este trabajo, y no solo los de este capítulo, nos llevan a la cuestión final: ¿cuáles son los elementos de la prefiguración de la comunidad que están contenidos en los movimientos antiglobalización, ciertamente de modo embrionario y cuyo futuro aún es incierto? ¿En qué medida los movimientos antiglobalización alcanzan al nivel de reciprocidad del don, teniendo como horizonte de sentido a la comunidad como el don absoluto, inalcanzable en las condiciones actuales de la humanidad? ¿Puede realizar el Foro Social Mundial la fraternidad mundial sobre otras bases diferentes de la sociedad capitalista?

Sobre estas preguntas no hay respuestas definitivas; por el contrario, el nivel de elaboración es precario. Sin embargo, podemos adelantar las siguientes consideraciones en la dirección señalada.

\section{Planetariedad}

El primer punto, esencial en estas reflexiones, es que la comunidad debe tener un carácter planetario y esto surge no tanto desde exigencias teóricas o de principio sino de las condiciones de la humanidad en el momento actual.

Dada la situación en la que vivimos, las soluciones solo pueden ser a escala mundial, porque la interrelación del conjunto de aspectos de la vida y de los colectivos sobre la Tierra ha llegado a tal nivel que sería inviable cualquier otra respuesta que no tuviera en cuenta dicha escala. O, de otra manera: puesto que la dominación se ha convertido en mundial por los fenómenos de la globalización, las resistencias también se globalizan. Esta globalización de las resistencias (Amin y Houtart, 2002) lleva a plantearse un conjunto de tareas mundiales, de cuya resolución dependerá el futuro de la humanidad. Se ubican por tanto del lado estricto de la biopolítica, en donde la vida entera sin excepción se encuentra en juego. 
Sin sostener que este sea un listado exhaustivo de tareas mundiales, son decisivas como problemas centrales que las sociedades contemporáneas asumen:

- El petróleo

- El agua

- La deuda externa

- La lucha contra la pobreza

- La lucha contra el patriarcado

- La batalla contra el racismo

- La exigencia de la paz mundial

Ninguna de estas grandes tareas podrá ser cumplida y resuelta sin una estrategia mundial; de hecho, el origen de los movimientos sociales antiglobalización proviene del carácter de la dominación mundial, que ha intervenido sobre cada uno de estos aspectos porque le son esenciales para su reproducción ampliada. La planetariedad de la comunidad se afirma sobre exigencias prácticas, actuales, en donde se ha colocado el futuro de la humanidad en cuestión y es preciso diseñar un camino para empezar a solucionarlo. Esta mundialización de las resistencias le da el primer contenido a la comunidad.

La comunidad que viene no podrá ser sino a escala mundial tanto para enfrentar los retos señalados como para escapar a las limitaciones históricas de las formas comunitarias que han existido hasta ahora, que serían claramente insuficientes para asumir los roles que las sociedades contemporáneas exigen que tome. Spivak propone reemplazar al globo por el planeta, a la globalización por la planetarización; aunque hablando inicialmente sobre otro tema, desemboca en reflexiones de carácter general; por esto, podemos aplicar a los movimientos sociales antiglobalización lo que ella propone:

... puede ser que intenten representarse a sí mismos -imaginarse a ellos mismos- como planetarios antes que como continentales, globales o mundiales. El planeta es fácilmente reclamable. Déjenme explicarles qué esfuerzo está implícito en mi invocación de tal mundo (Spivak, 2003: 72).

Porque solo en el planeta garantizamos la alteridad como uno de sus componentes esenciales y aprendemos que toda colectividad es siempre la confluencia de los diferentes, que para entrar en relación tienen que destrascendentalizarse. Lo que nos lleva a la necesidad de encontrar un sentido radicalmente 
de comunidad que aún se encontraría en formación como realidad y por ende como concepto:

Para hacerlo tuve que avanzar por una senda nada fácil, plagada de trampas léxicas y dificultades interpretativas pero que podrá conducir... a una noción de comunidad radicalmente distinta de las esbozadas hasta ahora (Esposito, 2003).

\section{Referencias bibliográficas}

Agamben, Giorgio. 2003. The coming community. Minneapolis: University of Minnesota Press.

Amin, S. y F. Houtart (eds.). Globalización de las resistencias, Forum Mundial de Alternativas, Icaria-Antrazyt-Cáritas Española. Barcelona. 2002.

Bauman, Zygmunt. Comunidad. En busca de seguridad en un mundo hostil. Madrid: Ed. Siglo XXI. 2003.

Derrida, J. 1995. Dar (el) tiempo, I. La moneda falsa. Barcelona: Ed. Paidós.

Espósito, Roberto. 2003. Communitas. Origen y destino de la comunidad. Buenos Aires: Ed. Amorrortu .

Estermann, Josef. 1998. Filosofía andina. Estudio intercultural de la sabiduría autóctona andina. Quito: Ed. Abya-Yala.

Fistetti, Franceso. 2003. Comunidad. Léxico de política. Buenos Aires: Ed. Nueva Visión.

Jean-Luc, Nancy Jean-Luc. The inoperative community. Minneapolis: University of Minnesota Press. 1991.

Rojas, Carlos. 1994. Mundos simbólicos y subjetividad. Cuenca: Universidad del Azuay.

Spivak, G.Ch. 2003. Death of a discipline. New York: Columbia University Press.

Weber, Marx. Economía y sociedad. México: Ed. Fondo de ultura económica. 1977. 